March 3, 2006

\title{
Reconciling the Returns to Education in Off-Farm Wage Employment in Rural China
}

\author{
Alan de Brauw and Scott Rozelle*
}

*Alan de Brauw is assistant professor, Department of Economics, Williams College, and Scott Rozelle is professor, Department of Agricultural and Resource Economics, University of California, Davis. Please direct all correspondence to Alan de Brauw, Department of Economics, Williams College, Williamstown, MA 01267 (e-mail: alan.d.debrauw@williams.edu; phone: (413)597-4373; FAX: (413)597-4045). We are grateful to Belton Fleisher, Qiuqiong Huang, Albert Park, J. Edward Taylor, Jim Wilen, Yigang Zhang, and an anonymous referee for comments on the manuscript. The authors acknowledge the support of the Ford Foundation, Beijing. Rozelle is a member of the Giannini Foundation of Agricultural Economics. 


\title{
Reconciling the Returns to Education in Off-Farm Wage Employment in Rural China
}

\begin{abstract}
Previous studies have found that the returns to education in rural China are far lower than estimates for other developing economies. In this paper, we seek to determine why previous estimates are so low and provide estimates of what we believe are more accurate measures of the returns. Whereas estimates for the early 1990s average 2.3 percent, we find an average return of 6.4 percent. Furthermore, we find even higher returns among younger people, migrants, and for post-primary education. The paper demonstrates that, although part of the difference between our estimate and previous estimates can be attributed to increasing returns during the 1990s, a larger part of the difference is due to the nature of the data and the methodological approaches used by other authors.
\end{abstract}




\section{Reconciling the Returns to Education in Off-Farm Wage Employment in Rural China}

Rural education is of primary importance to development in China. Since family planning policies were implemented, birth rates have been much higher in rural areas than in urban areas. As approximately 60 percent of China's population permanently resides in rural areas, an even larger percentage of children are educated in rural areas (CNBS, 2005). Therefore, the effectiveness of rural education is of particular interest to policy makers and researchers interested China's continuing development.

Despite the importance of building human capital in rural China, education has not had a prominent role in government development efforts during the past two decades, and faces serious fiscal problems (West, 1997; Nyberg and Rozelle, 1999). Unlike its successful neighbors in East Asia, China's central government has traditionally spent relatively little on rural education. For example, Heckman (2005) reports that China as a whole spent $2.5 \%$ of GDP on education, while the world average is $5.2 \%$. Governments of other developing countries in Asia typically spend between 4 and 5\%. Rural education attainment rates also are relatively low for China's level of development. In China, the average educational attainment was only 6.1 years in the $1990 \mathrm{~s}$, compared with more than eight years in the rest of Asia (Psacharopoulos, 1994).

Education may be underfunded in China in part because investments in rural education are perceived to generate relatively low private and therefore social rates of return. While measured average returns to education in the developing world are over 10 percent and exceed 9 percent in other Asian countries (Psacharopoulos, 1994), studies in rural China typically estimate returns below 5 percent. In the urban economy, studies using data collected in the late 1980s and early 1990s rarely found returns to exceed 5 percent (e.g. Meng and Zhang, 2001). ${ }^{1}$ Studies of the rural economy have typically found even lower returns (e.g., Parish, Zhe, and Li, 1995). If previous studies are correct and investment in schooling in China does not lead to higher incomes, one can argue that China's government should reduce its emphasis on schooling in its development plan in 
favor of other expenditures that will lead to higher returns.

As returns to education are relatively high in other countries, consistently low estimates of returns in rural China demand further explanation. Given its socialist legacy, it is possible that China's reformers may have insulated managers from the pressures of markets. Managers may have been encouraged to use non-market factors to assign jobs to workers rather than hiring more educated workers or workers with better qualifications. While this explanation is plausible for the early years of transition in urban China, it is unlikely to be the major reason for low returns in the rural economy, as it became market-oriented much earlier in the market transition than the urban economy. Rural enterprises have operated in an increasingly competitive environment, and managers in most fields have had fairly good incentives and rights (e.g. Jin and Qian, 1998).

Alternatively, the returns to education in rural China may have been systematically underestimated due to methodological shortcomings. Previous studies may have mis-measured wages by using a wage measure that endogenizes part of the individual's decision regarding the amount of labor to allocate to off-farm work. If so, wages for the educated could be systematically understated relative to the less educated. Using data that allow for a more appropriate measure of the wage- the hourly wage instead of a daily or monthly wage- might help provide better estimates. Previous studies have also focused on only one sector of the rural off-farm economy. If that sectorfor example, rural industry- was dominated by firms with managers that did not reward workers for their education, low measured rates of return may reflect the fact that surveyed firms were simply not representative of the rural economy as a whole. Moreover, returns could be lower for low levels of education (primary school) than for higher levels of education (lower and upper secondary school). Treating each year of education as the same could lead to systematic underestimates of the returns to education when, as in rural China, the average educational attainment level is relatively low primary school completion (Strauss and Thomas, 1995). Regardless of the source of bias, if low estimates of the rate of return to schooling are primarily due to methodological shortcomings, previous research may have justified low investment in education rather than helping China catch 
up with the rest of East Asia.

The goal of this paper is to help explain the difference between estimated returns to education in off-farm employment in rural China and the rest of the world. We produce new estimates of the returns to education in rural China and reconcile our results with those in the literature. While earlier studies may find low returns due to institutional constraints, we show methodology significantly contributed to the low measured rates of return in the human capital literature on rural China. We show that three factors helped lead to these low measurements- mis-measured wage rates, unrepresentative samples, and a failure to account for the non-linearity of returns to education. Methodological differences between our study and others account for a significant part of the difference between educational rates of return in rural China and the rest of the world. In fact, a subset of our estimates are consistent with the average returns to schooling found in East Asia (Psacharopoulos, 1994).

To accomplish this goal, the paper proceeds as follows. The first two sections describe our data set and examine previous work on wages and rates of return in rural China. The third section describes the empirical framework we use to produce estimates of rural rates of return to education. The fourth section presents the results, examines how the estimates change when alternative specifications, samples, and estimation techniques are used, demonstrates how specific assumptions can explain the previous results in the rural China education literature, and shows that relaxing those assumptions make rural China's estimates consistent with the rest of the world. The final section concludes.

\section{Data}

The data set used in this paper is from a nearly nationally representative survey of 1199 households in 6 provinces and 60 villages in rural China conducted by the authors in late $2000 .^{2}$ In addition to collecting basic information on the farm household, land and labor endowments, and other production-oriented activities, the survey included detailed information about labor force participation and schooling among all household members. Enumerators questioned all household 
members about their education, and asked all household members about their employment and work except for children under fifteen, individuals in school, and the elderly who no longer work. In total, our sample includes 3364 individuals who were 16 years of age or older and could potentially work. Of those, 1023 individuals worked for a wage off the farm either locally or as a migrant, and 2341 did not.

To assess the representativeness of our sample, we compare the agricultural labor force participation rate in our sample with statistics published by the China National Bureau of Statistics (CNBS) for 2000 (CNBS, 2001). Ideally, the raw participation rate in our sample would be equivalent to the rate published by CNBS, but some differences should be expected due to differences in survey techniques. The CNBS only reports the amount of farm sector employment in rural areas, and does not include migrants as rural laborers. For our survey, enumerators were trained to include migrants as household members. Furthermore, our sample includes detailed time allocation data, allowing individuals to be included in more than one employment category. When we control for these differences, we find our sample is largely consistent with the national statistics (Table 1). According the CNBS, $67 \%$ of rural laborers were primarily employed in agriculture (row 1). In our entire sample, we find that $76 \%$ of workers spent some time working in agriculture (row 2). Although our sample might seem systematically different than that of CNBS at first glance, differences in survey techniques account for almost the entire difference. Relative to the CNBS, the inclusion of migrants should bias our estimate upwards, while the inclusion of multiple job categories should bias our estimate downwards. When we both exclude migrants and limit individuals to work in the sector in which they spent the most time, our farm sector employment estimate is $67.6 \%$ (row 4), or almost the same as the CNBS. Hence, at least according to farm participation data, our survey seems remarkably consistent with the national statistics.

Several aspects of both our household and village level surveys were designed specifically to try to help answer questions about rural China's rates of return to rural education. The survey asked about school participation using both the years a person was in school and the final level of school 
attainment, and specifically asked if people repeated grade levels. Hourly wages were computed by taking all monetary earnings over the course of the year (in multiple jobs, if the person held more than one wage earning job) and dividing by the total number of hours that were reported as being worked during the year. The survey specifically asked respondents whether or not they lived at home while they were working, so they could be categorized as local wage earners or migrants. ${ }^{3}$ To proxy for individual ability, which is known to bias estimates of the returns to schooling, we follow Ashenfelter and Zimmerman (1997) and use questions enumerators asked about the years of schooling each person's parents attained.

\section{Returns, Educational Attainment, and Methodological Shortcomings}

Meta-analyses of studies of the returns to education show a striking regularity in the relationship between wages and schooling levels in developing countries (Figure 1). ${ }^{4}$ In Sub-Saharan Africa and Latin America, where average educational attainment is between 5 and 8 years, an individual who attends an additional year of schooling gains a return of more than 12 percent annually in the form of increased wages. In Asia and the Middle East, where average educational attainment is higher, rates of return, although somewhat lower, still typically range between 8 and 10 percent (Psacharopoulos, 1994). The average return in the OECD countries, where most of the population graduates from high school, is about 7 percent.

In rural China, although the average level of educational attainment has risen in recent years, it is much lower than in the rest of Asia (Figure 1). Among the entire workforce, the average years of schooling is 6.13 years. Among workers 35 years old and younger, the average education level is much closer to the level in the rest of Asia, at 7.59 years. Education levels have increased among young people as a result of educational reforms that have, among other changes, mandated that children go to school for nine years. However, there is no guarantee that students go to school for the mandated nine years, especially in poor areas (Tsang, 1996; Brown and Park, 2002).

The pattern of educational attainment and returns found in rural China does not fit the pattern found in the rest of the world. In rural China, estimates of the return to schooling made by other 
researchers are consistently quite low (Table 2). We identified six studies of rates of return in rural China that have used standard Mincerian methods. ${ }^{5}$ The average return across these studies is about 4 percent. Only one of the studies, Ho et al. (2002), measures returns in excess of 5 percent. Plotted on Figure 1, rural China stands out as having abnormally low rates of return to education when compared with the rest of the world, given its average educational level.

In addition to the experience of other developing countries, there are other reasons to believe that returns to education may be higher than current published estimates. For example, in our data wages are positively correlated with education levels (Table 3). Among individuals who work for a wage off-farm, wages are significantly higher among people who have attended at least some postprimary school than among people who have not (row 1). Wages are also higher among migrants and younger workers who are more educated (rows 2 and 4). For example, migrants who have post-primary education have an average wage of 2.92 yuan per hour, whereas wages average 2.25 yuan per hour among migrants with a primary education or below.

The method of measuring wages in the previous studies of rural China's returns to education may have further affected the estimates of the returns to education. In countries with underdeveloped financial markets, such as China, poorer people may drop out of school because they cannot finance the earnings they forego to attend school, while richer people can continue as they wish (Schultz, 1988). As a result, richer people may systematically have more education. Moreover, differences in wealth endowments, which are associated with differences in preferences for leisure and tolerances for risk, may influence the relatively poor to work more after completing their education. Therefore the poor may have to work either more hours per day and/or more days per month or year, and estimates of the returns to education based on daily, monthly or annual earnings could underestimate the true returns to schooling. Since hourly income is not affected by the choice of how many hours per day or days per month to work, it is the preferred measure (Schultz, 1988; Card, 1999). None of the previous Mincerian studies in rural China use hourly wages.

Methodological issues related to the use of unrepresentative samples may further obscure 
the measured relationship between wages and completed education. Several papers only consider workers in one industry or sector of the economy (e.g. Meng, 1996; Gregory and Meng, 1995; Ho et al., 2002). If that sector had lower rates of return than other sectors, perhaps for institutional reasons, estimates drawn from such studies would not be representative. Becker (1964) warns that estimates of educational returns will be low if particular groups of workers are singled out for estimation, because the effect of selection into that portion of the off-farm labor force is ignored. Only one paper in the rural China literature does a standard Heckman correction for sample selectivity bias (Zhang et al., 2002).

Finally, previous studies have not considered several other basic empirical issues. For example, the returns to education in rural China have not addressed criticisms of the Mincer method that are well known in the literature (e.g. Schultz, 1988; Strauss and Thomas, 1995; Card, 1999). For example, none of the Mincerian studies controlled for potential non-linearities in returns. ${ }^{6}$ Several recent studies based on urban China have found highly non-linear returns to education (e.g. Giles et al., 2006). If returns to post-primary education exceed the returns to primary education in rural China, and previous studies systematically excluded classes of more educated workers, their estimates would have been biased downward. As education is positively correlated with migration (Zhao, 1999; Rozelle et al., 1999), if other studies missed or excluded migrants, their estimated returns might be biased downward. Furthermore, previous studies have not controlled for potential sources of omitted variable bias, such as measures of individual ability.

\section{Modeling the Effect of Schooling on Income}

While it may not be surprising that the current literature has not found rates of return in rural China that fit the patterns found elsewhere, ex ante we do not know what factors cause such low estimates. To address these shortcomings, we produce new estimates that use methods that will attempt to address such criticisms. Therefore, in this section, we first present a model commonly used to estimate the returns to education (Mincer, 1974). The model is subject to several criticisms, which can be categorized as either problems that result from measurement issues or omitted variable 
biases. After summarizing the model, we will discuss econometric strategy to address the issues.

\subsection{The Mincer Model}

Mincer (1974) proposed a simple model relating years of completed schooling to lifetime earnings. The model initially assumes that risk neutral individuals will work over a fixed lifespan of $W$ years, and their human capital stock does not change after they complete their schooling. Furthermore, the income that an individual will obtain is fixed and related directly to the amount of schooling they obtain. In this model the private cost of schooling is the cost of delaying the income stream another year, implying the relationship:

$$
\ln \left(Y_{s}\right)=\ln \left(Y_{0}\right)+r S
$$

where $Y_{s}$ is the income after schooling, $Y_{0}$ is the base income with no schooling, and $S$ is the years of schooling completed. In our analysis, we use hourly wages as the income measure.

Studies of the returns to education modify equation (1) to account for post-schooling human capital accumulation, through experience, and sometimes other effects on wages or income (Psacharopoulos, 1994). If experience, E, and experience squared are used to control for postschool human capital accumulation, the return to schooling, $r$, for individual $i$ can be determined by estimating:

$$
\ln \left(Y_{s, i}\right)=\ln \left(Y_{0}\right)+r S_{i}+\beta_{1} E_{i}+\beta_{2} E_{i}^{2}+\varepsilon_{i}
$$

Equation (2) is typically referred to as the Mincer "earnings function" method of determining the returns to schooling, and literally hundreds of studies have estimated the above equation in various settings. In all specifications, we modify equation (2) by adding several dummy variables. First, we add a variable that indicates whether or not an individual has received formal training for a profession or trade to account for any wage premium paid for such training. Second, we include a gender dummy variable, to control for the possibility that men and women are paid different base wages. Third, we include provincial dummy variables in all equations to account for different 
base wage rates. ${ }^{7}$ Finally, since marital status has been found to affect wage rates in developed countries (e.g. Goldin, 1990), in most specifications we include a dummy variable for whether or not individuals in our sample are married.

\subsection{Further Adjustments to the Mincer Model}

If we simply estimate equation (2) using OLS, we run into several potential biases, and therefore we adjust our estimation framework to account for them. ${ }^{8}$ Following Heckman (1974), workers will not enter the workforce if their reservation wage $\left(Y^{*}\right)$ is higher than the wage offered. In rural China, people do not only make a choice between off-farm labor and leisure; they can also work in farming, raising livestock, and in self-employment. Their individual reservation wage is therefore determined by other opportunities and/or tradeoffs between labor and leisure. If that reservation wage is higher than the wage offered for an individual's skill set, that person will not enter offfarm labor markets. From the analyst's perspective, we only observe wages for individuals who are offered a wage $Y_{s, i}>Y^{*}$. If we do not correct for this selectivity bias, the estimated return to education in off-farm work may be biased downward.

To account for this potential bias, we first estimate a probit for all individuals in our sample, where the dependent variable is one if the individual works off-farm for a wage and zero otherwise. Using the results of from the probit estimation, we compute an inverse Mills ratio that corrects for possible truncation of the dependent variable in estimation of equation (2). In order to identify the probit equation, we include the logarithm of the household's asset holdings in 1999, the number of males and females of working age in the household, and the land endowment granted to the household by the village. We believe these variables can identify the participation effect since none of these variables should affect the hourly wage of a specific worker, except through his/her decision about whether or not to participate in off-farm wage labor. Moreover, we hypothesize that the instruments should have an effect on an individual's reservation wage, by affecting the returns to labor on the farm, in self-employment, and in leisure. ${ }^{9}$

Equation (2) also implicitly assumes that the returns to education are the same for each 
additional year, even when individuals change schools. The returns could be non-linear; that is, the returns to different levels of schooling may be different. To account for variation in the returns to different levels of schooling, we modify our model to estimate the return to an additional year of primary school and a separate estimate for an additional year of post-primary school. We modify equation (2) to estimate different coefficients for the return of primary schooling, $r_{P}$, and the return to post-primary schooling, $r_{M}$ :

$$
\ln \left(Y_{s, i}\right)=\ln \left(Y_{0}\right)+r_{P} P_{i}+r_{M} M_{i}+\beta_{1} E_{i}+\beta_{2} E_{i}^{2}+\varepsilon_{i v}
$$

where $P_{i}$ represents the years of primary school completed by individual $i$, and $M_{i}$ represents the years of post-primary school. If an individual left school before completing primary school, then $M_{i}$ is equal to zero.

Additionally, the Mincer model has been criticized for potentially omitting variables correlated with both wage levels and schooling, therefore implying bias in the estimated return to schooling. Many authors have pointed out that if people with more ability to earn money tend to go to school longer, then the estimated return to schooling will be biased upwards (e.g. Boissiere, Knight, and Sabot, 1985). Therefore, we check the robustness of our results to the inclusion of variables that proxy for an individual's ability. Following Ashenfelter and Zimmerman (1997) among others, we attempt to control for individual ability using the educational attainment of the individual's mother and father as proxies.

\section{Results}

To generate estimates of the rates of return to education, we estimated equation (2) while controlling for sample selectivity bias (Table 4). By several measures, the estimator performed well. The Wald test statistic for the hypothesis that all coefficients were zero was strongly rejected, and OLS versions of the wage equations had $R^{2}$ statistics ranging from 0.15 to 0.20 . Moreover, most coefficients are of the expected sign and statistically significant. For example, in all but one of the reported specifications we find the expected concave relationship between wages and years of 
experience. As described by other authors who have examined the determinants of participation in the off farm labor market (e.g. Zhao, 1997), we find that education has a strong effect on selection into the off-farm labor force. At the mean level of education in the sample, an additional year of education is associated with being 1.1 to 1.3 percent more likely to find an off-farm job (Appendix Table 2, row 1).

In addition to helping people find off-farm jobs, education has a positive, statistically significant effect on hourly wages. Depending upon the specification, we find that the average return to a year of education was between 6.3 and 6.5 percent (Table 4, columns 1-3). Initially, we estimate the average return to education to be 6.3 percent (column 1). Next, we include marital status to control for potentially higher wages among married individuals (Goldin, 1990), and find that marital status seems to have a negative effect on participation, and no effect on wages (column 2). Third, we test for ability bias by including the educational attainment levels for each individual's parents (column 3). These variables affect neither off-farm participation nor the wage rate, so we choose the model in 2 as our preferred specification. Therefore, using our entire data set and the basic specification, our estimate of the average return to education is 6.4 percent.

All three estimates are higher than other nationally representative samples from rural areas listed in Table 2 (e.g. Parish et al., 1995; Johnson and Chow, 1997). One possible reason that our estimate is higher is that we used a different methodological framework than other studies, through the hourly wage definition and controlling for selectivity into off-farm employment. Alternatively, the higher estimate could be due to the fact that we used a more representative sample, containing observations from across China and including both local wage earners (i.e., workers that have a job in local manufacturing or service enterprises) and migrants, instead of a subsample of local wage earners (e.g. Meng, 1996; Ho et al., 2002). Finally, the rate of return to education could be increasing over time, and our estimate could be relatively high because we used more recently collected data. Despite the use of a more recently collectedd nearly nationally representative sample and a more theoretically consistent wage measure, our base estimate is still lower than estimates 
normally found for other developing countries.

The rates of return to education, however, rise sharply when the analysis focuses on specific age groups within the population. Among individuals aged 35 and under, the average rate of return to a year of education rises to 10.5 percent (Table 4; column 4). This estimate is consistent with the average return found in the rest of Asia. While education selects individuals over 35 into wage earning jobs, it does not have a large effect on earnings. The point estimate for the returns to schooling among individuals over 35 is 2.9 percent, and it is only statistically significant at the 10 percent level (row 1, column 5). The difference between returns for younger and older workers may indicate that human capital is becoming increasingly important for younger workers in rural China, the group that makes up the largest and fastest increasing part of China's off-farm labor force.

Of course, the off-farm employment decision is in reality more complicated than a simple farm/off-farm decision. In reality, working individuals choose among several options, which can broadly be categorized as working on the farm, earning wages locally, self-employment, and entering the migrant labor force. To determine whether education had different effects on entrance into different sectors of the off-farm labor market, we first ran a multinomial probit in which the base category is farming. The analysis was performed for both the entire sample and for individuals aged 35 and under (Appendix Table 3). Although education is only positively associated with local wage labor and self-employment relative to farming among the whole sample (columns 1-3), when the sample is restricted to individuals aged 35 and under education helps push young people into all three of the off-farm employment subsectors (columns 4-6). Furthermore, the estimated coefficients are similar, implying that education has similar effects on increasing the likelihood of all three types of off-farm employment. These results are consistent with Yang and An (2002), who show education helps push rural residents into off-farm employment, and Zhang et al. (2006), who find education has a positive effect on predicting self-employment.

To determine the returns to education among migrants and local wage laborers, we use the 
multinomial probit estimation to construct inverse Mills ratios, and then separately estimate equation (2) for migrants and local wage laborers. Each equation is estimated for both the whole sample and for individuals aged 35 and under. Among migrants, the rate of return significantly exceeds the national average. When examining the entire sample, we find that migrants earn an 8.0 percent return to a year of schooling, whereas local wage earners earn 3.3 percent, and the latter estimate is only significant at the 10 percent level (Table 5; row 1, columns 1 and 2). When we restrict the sample to individual migrants 35 years old and under, we find that the rate of return rises to 11.9 percent (row 1, column 3). Local wage earners among younger individuals in the sample also earn a significant return to their labor, of 9.2 percent. If migrants, and particularly young migrants, are systematically excluded from samples measuring the returns to rural education, the estimated rate of return could be biased downward.

The returns to education in rural China might also be underestimated if, for example, later years of schooling lead to larger wage increments than earlier years of schooling. To test whether this phenomenon occurs in rural China, equation (3) was estimated using the whole sample and for individuals aged 35 and under (Table 6). Though primary education has a positive, statistically significant effect on selection into off-farm work in general (row 1, column 1), the return to a year of primary schooling is only 3.9 percent, and only marginally statistically significant (row 1 , column 2). In contrast, post-primary schooling has a large, significant effect on the wage received (row 2, columns 2 and 4). Individuals who find jobs receive a return to an additional year of postprimary schooling of 7.4 percent (row 2; columns 2). ${ }^{10}$ These findings are consistent with a story that more educated workers were relatively scarce in rural China during the 1990s, and therefore they were receiving a high return to their education level. Using a data set collected in urban China, Li (2003) finds a similar low return to primary schooling and suggests that the returns to primary school are low because nearly every child now completes primary school. 


\subsection{Reconciling with Other Studies on Rural China}

In order to reconcile our estimates for the rate of return to education in rural China with the findings of other authors, we perform the following set of exercises. First, we attempt to determine how much of the difference between our estimates and previous estimates are due to the difference in the time the data was collected, henceforth the timing effect. To do so, we use our data set

to mimic the analyses of previous Mincerian studies (Table 2). ${ }^{11}$ We follow each author's wage definition and econometric specification as closely as possible, and then re-estimate the Mincer model. Since none of the previous authors did so, in this step we do not correct for selectivity. Where appropriate, we also restrict our sample either geographically or to a certain portion of the off-farm labor force. The difference between original published estimates and the estimates using our data and the specifications used by previous authors is one way to determine whether the return to education has changed over time.

Second, we attempt to find out how much of the differences in rates of return are due to methodological considerations. We can identify two effects. First, we primarily set out to determine how much of the difference is due to the mis-measured wage, controlling for sample selectivity. After using our data to mimic the original analyses, we make corrections in the wage definition and control for selectivity for all five studies, and re-estimate each model. From this part of the exercise, we can determine how much of the difference in the results are from the definition of the dependent variable (and selectivity). As two studies focused solely on the TVE sector, yielding an incomplete sample of the rural labor force (Meng, 1996; Gregory and Meng, 1995), here we use their specification and estimate returns using the entire sample, including migrants.

Our experiments show that the timing effect accounts for a portion of the difference between our estimates and the lower estimates found in the literature (Table 7, columns 1 and 2). When we compare the original rates of return from the literature (that use data collected in years varying from the late 1980s to the mid-1990s) with the estimates that use our data (from 2000) but their specifications and wage measurements, rates of return rise in four of the five cases when we use 
our data (column 2). On average, the rates of return rise from 2.3 to 3.8 percent, an increase of 1.5 percent. ${ }^{12}$ While some of the gap that we observe between the rural China literature and the rest of the world is due to a timing effect, which could be linked to the increasing emergence of labor markets, the rise in returns is modest. Furthermore, China's rates are still far below those in the rest of the world.

The methodological part of the experiment accounts for an even greater part of the gap (Table 7). After replacing each study's wage definition with the hourly wage and controlling for selectivity, we find that the rates of return return rise for all studies (columns 2 and 3). In the first three studies, we only test the mis-measured wage effect, and find the largest increase using the specification of Johnson and Chow (1997). For their study, the rates rise from 3.0 to 6.5 percent (row 1). For Parish et al. (1995) and Yang (1997), the increases are more modest, but still increase by 0.7 and 1.8 percent, respectively (rows 2 and 3). Since the final two studies only examined local wage earners, we control for both the mis-measured wage and for an unrepresentative sample (Meng, 1996; Gregory and Meng, 1995). While the mis-measured wage effect is found to be positive, the return only increases by 1.2 percent ( 4 percent versus 2.8 percent- not shown). However, when we include migrants when estimating the returns using their specification, the returns rise even further to 6.1 percent (column 3, rows 4 and 5). In total, the methodological adjustments raise the rates of return, on average, from 2.7 to 6.1 percent (row 6), accounting for a larger increase than the timing effect.

Although the timing effect and the two effects associated with methodology help close the gap between the China literature and the rest of the world, part of the gap still remains. Some of the gap may be due to the nonlinearity of returns. If returns to post-primary education are inherently higher in rural China, and educational attainment levels are low, part of the gap may be caused by the fact that a smaller portion of its population is receiving the type of education that creates higher returns. Besides finding this effect in the previous section (Table 6), we also find it using the specifications of other authors. After making the corrections for wage definitions and sample 
selectivity bias, we find the returns to post-primary school are systematically higher than primary school in all of the studies, and range between 6.7 and 9.0 percent. The returns to a year of postprimary school are between 2.3 and 4.9 percent higher than the returns to primary school. As a result, by not considering the possibility of a convex relationship between wages and education, all previous studies may have further underestimated the returns to post-primary schooling.

Beyond methodological differences, part of the difference between returns in China and the rest of the world may also have to do with labor force demographics. Because birth rates in China declined earlier than in other parts of the developing world, the nation's rural labor force is relatively older than that of other developing countries (e.g. Tu, 2000). To provide a better comparison of China's labor force to that of the rest of the world, we concentrate on the rate of return to education among the young. ${ }^{13}$ If we revisit the illustration using the data from Psacharopoulos (1994), we see that the timing of our study, methodology, and the evolution of the labor force account for almost all of the gap in rates of return and attainment. Correcting for timing and methodology, we boost rates of return from around 4 to a rate of return of 6.4 percent at an average level of schooling attainment of around 6 years (Figure 2). When we restrict the sample to individuals under 35 years

old, the rate of return increases to 10.5 percent, at an average schooling level of 7.5 years. When we plot this point on Figure 2, it is precisely in line with the rates of return and attainment rates found in the rest of the world.

\section{Conclusions}

In this paper, we have used a nearly nationally representative sample of workers in rural China to estimate the returns to education in off-farm work. Making corrections for selectivity into off-farm work and using the hourly wage rate, we find that across all individuals with off-farm jobs in our sample, the mean return to a year of education is 6.4 percent. The estimated return is even higher among all migrants in the sample, at 7.8 percent. These estimates are higher than most previously reported estimates of the return to education in China in the economics literature.

When the sample is restricted to individuals who are aged 35 and under, we find that the 
returns to education are 10.5 percent, which equals the average return found in Asia (Psacharopoulos, 1994). Among migrants, the return to a year of education is even higher, around 11.7 percent. Furthermore, the returns to education exhibit some convexity, which is consistent with findings of other authors who have looked for non-linearities in the returns to education in other developing countries (e.g. Strauss and Thomas, 1995; Duflo, 2001) and in urban China (Li, 2001; Zhang et al., 2005). The estimates are also robust to controls for individual ability, which might have biased the returns downward.

Our study shows the importance of using reasonably sound methodology on data sets that are representative of the entire wage earning labor force. When we replicate the methods followed by other authors to estimate returns to education using these data, we find that their methodology is associated with lower estimates of the returns to education. The results of this exercise emphasize the need to use hourly wages, rather than daily or monthly wages, to control for the amount a person chooses to work, as highly educated people in developing countries tend to choose to work less. They also show the importance of choosing a representative sample when studying the returns to education; we find that returns to education tend to be lower when only local labor is studied, as the returns to education in China are higher for migrants.

Finally, our estimates show that increasing educational availability in rural areas may be a good policy instrument for increasing rural incomes, particularly with respect to post-primary school. This paper finds that the returns to education among younger workers are at approximately the same level as returns to schooling in the rest of Asia, and in developing countries in general. Given these high private returns, China's government would do well do make rural education a top priority. As the majority of children in China today are being raised in rural areas, much of China's future labor force would be made better off by supporting their education. 


\section{Notes}

${ }^{1}$ More recently, several authors have estimated much higher rates of return to education in urban areas of China (e.g. Zhang et al., 2005).

${ }^{2}$ The provinces included in the survey were Hebei, Shaanxi, Liaoning, Zhejiang, Sichuan, and Hubei, and the sample is evenly split between the six provinces. Descriptive statistics for all variables included in the regressions in the paper are in Appendix Table 1.

${ }^{3}$ We define migrants as individuals who are still considered household members, but lived outside the household for at least one month during the year while working. Although the CNBS (2001) does not categorize migrant workers as part of the rural labor force, most analysts consider them rural workers in China. Moreover, many migrants in our sample work in rural areas; only half of them leave their home county.

${ }^{4}$ Meta-analyses of studies of the returns to education average estimates over samples with differing levels of representativeness as well as over different periods of time. Some of the studies included in the averages presented here may share the methodological shortcomings of the literature on the returns to education in rural China. To the extent that these averages share these shortcomings, we would argue that they represent estimates that are biased slightly downward. Because they are averaged across many different studies, they should be considered crude estimates, although representative of the pattern.

${ }^{5}$ We define the "standard Mincerian method" as regressing the years of education, years of experience, and years of experience squared on the logarithm of a wage variable while using a sample of individuals. Several studies not included in Table 2 calculate the returns to education using other methods; see de Brauw (2002) for a summary.

${ }^{6}$ Two previous studies attempted to explicitly control for a potential nonlinear relationship between wages and completed schooling by including an "education squared" variable (Zhang et al., 
2002; Yang and An, 2002).

${ }^{7}$ Since a sizeable proportion of migrants in our sample leave their home province, one might be concerned that their base wage rate is different than the base wage rate for their home province. Unfortunately, our survey did not ask about the destination province of migrants, so we cannot include a full set of provincial dummies. We did check whether our results were robust to including a set of separate dummy variables for migrants who worked outside their home province (one for each province). As we found no difference between those results and the results when using provincial dummies, we report the latter, more parsimonious specification.

${ }^{8}$ Although we deal with several of the criticisms of the Mincer model in this paper, it has further criticisms that we will not discuss here. For example, it does not take into account regional labor supply and demand relationships that may affect the return to education in one place but not another (Heckman et al., 1996).

${ }^{9}$ The results in the paper are robust to the exclusion of specific instruments from the selection equation as well as their inclusion in the wage determination equation.

${ }^{10}$ Among younger workers, the returns are also convex. Although the point estimate of the return to primary schooling is somewhat larger, at 6.0 percent, it is only statistically significant at the 10 percent level. However, conditional on holding a job, they receive a return of 11.5 percent to each year of post-primary schooling.

${ }^{11}$ We did not replicate the Ho et al. (2001) study, as it covered specific TVEs in Shandong and Jiangsu provinces, which are not included in our sample.

${ }^{12}$ To make this calculation, we take the average of men (1.8\%) and women (4.3\%) from the Parish et al. (1995) study (row 2).

${ }^{13}$ Furthermore, the education of those between 35 and 50 years old in China may have been severely affected by the Cultural Revolution. Therefore, it is probably inappropriate to consider a year of education during the Cultural Revolution and after the Cultural Revolution as the same. 


\section{References}

Appleton, Simon, John Knight, Lina Song, and Qingjie Xia, 2002, Towards a Competitive Labour

Market? Urban Workers, Rural Migrants, Redundancies and Hardships in China, Institute for Contemporary China Studies Working Paper. Nottingham: University of Nottingham.

Ashenfelter, Orley, and David Zimmerman, 1997, Estimates of the Returns to Education from Sibling Data: Fathers, Sons, and Brothers, Review of Economics and Statistics 79(1), 1-7.

Becker, Gary, 1964, Human Capital (Columbia University Press, New York).

Boissiere, M., J.B. Knight and R. Sabot, 1985, Earnings, Schooling, Ability, and Cognitive Skills, American Economic Review 75(5), 1016-1030.

Brown, Phil and Albert Park, 2002, Education and Poverty in Rural China, Economics of Education Review 21(6), 523-541.

Card, David, 1999, The Causal Effect of Education on Earnings, Handbook of Labor Economics (Elsevier Science Publishers, Amsterdam), Orley Ashenfelter and David Card, eds., Volume 3A, Chapter 20, pp. 1801-1863.

China National Statistics Bureau, 2001 and 2005, China Statistical Yearbook. Beijing: China Statistics Press.

de Brauw, Alan, 2002, Three Essays on migration, Education, and Development in Rural China, Unpublished Ph.D. Dissertation, University of California, Davis.

Duflo, Esther, 2001, Schooling and Labor Market Consequences of School Construction in Indonesia: Evidence from an Unusual Policy Experiment, American Economic Review 91(4), 795-813. 
Giles, John, Albert Park, Meiyan Wang, and Juwei Zhang, 2006, The Great Proletarian Cultural Revolution, Disruptions to Education, and Returns to Schooling in Urban China, working paper, Michigan State University.

Gregory, R.G., and Xin Meng, 1995, Wage Determination and Occupational Attainment in the Rural Industrial Sector of China, Journal of Comparative Economics 21, 353-374.

Heckman, James, 1974, Shadow Prices, Market Wages, and Labor Supply, Econometrica 42, 67994.

Heckman, James, 2005, China’s Human Capital Investment, China Economic Review 15(1), 50-70. Heckman, James, Anne Layne-Farrar, and Petra Todd, 1996, Human Capital Pricing Equations with an Application to Estimating the Effect of Schooling Quality on Earnings, Review of Economics and Statistics 78(4), 562-610.

Ho, Samuel, Xiaoyuan Dong, Paul Bowles, and Fiona MacPhail, 2002, Privatization and Enterprise Wage Structures During Transition: Evidence from China's Rural Industries, Economics of Transition, 10(3), 659-688.

Jin, Hehui, and Yingyi Qian, 1998, Public versus Private Ownership of Firms: Evidence from Rural China, Quarterly Journal of Economics, 773-808.

Johnson, Emily N., and Gregory C. Chow, 1997, Rates of Return to Schooling in China, Pacific Economic Review 2(2), 101-113.

Meng, Xin, 1996, An Examination of wage determination in China's rural industrial sector, Applied Economics 28, 715-724.

Meng, Xin, and Junsen Zhang, 2001, The Two-Tiered Labor Market in Urban China: Occupational 
Segregation and Wage Differentials between Urban Residents and Rural Migrants in Shanghai, Journal of Comparative Economics 29, 485-504.

Mincer, Jacob, 1974, Schooling, Experience, and Earnings (Columbia University Press, New York).

Nyberg, Albert, and Scott D. Rozelle, 1999, Accelerating China's Rural Transformation (World Bank, Washington D.C.).

Parish, William, Xiaoye Zhe and Fang Li, 1995, Non-farm work and marketization of the Chinese countryside, The China Quarterly 143, 697-730.

Psacharopoulos, George, 1994, Returns to Investment in Education: A Global Update, World Development 22(9), 1325-1343.

Rozelle, Scott, Li Guo, Minggao Shen, Amelia Hughart, and John Giles, 1999, “Leaving China’s farms: Survey results of new paths and remaining hurdles to rural migration," The China Quarterly $158,367-393$.

Schultz, T. Paul, 1988, Education Investments and Returns, in Hollis Chenery and T.N. Srinivisan, eds., Handbook of Development Economics, Volume I (Elsevier Science Publishers: Amsterdam), 544-630.

Strauss, John, and Duncan Thomas, 1995, Human Resources: Empirical Modeling of Household and Family Decisions, in Jere Behrman and T.N. Srinivisan, eds., Handbook of Development Economics, Volume 3A (Elsveier Science Publishers: Amsterdam), 1885-2023.

Tsang, Mun C., 1996, Financial Reform of Basic Education in China, Economics of Education Review 15(4), 423-444. 
Tu, Ping, 2000, Trends and Regional Differentials in Fertility Transition, chapter 3 in: Xizhe Pen and Zhigang Guo, eds., The Changing Population of China (Blackwell Publishers: Malden, Massachusetts), 22-33.

West, Lorraine A., 1997, Provision of Public Services in rural PRC, chapter 6 in Financing Local Government in the People's Republic of China, Christine Wong, ed. (Hong Kong, Asian Development Bank), pp. 213-282.

Yang, Dennis T., 1997, Education and Off-Farm Work, Economic Development and Cultural Change 45, 613-632.

Yang, Dennis T., and Mark An, 2002, Human Capital, Entrepreneurship, and Farm Household Earnings, Journal of Development Economics 68(1), 65-88.

Zhang, Junsen, Yaohui Zhao, Albert Park, and Xiaoqing Song, 2005, Economic Returns to Schooling in Urban China, 1988-2001, Journal of Comparative Economics 33, 730-752.

Zhang, Linxiu, Jikun Huang, and Scott Rozelle, 2002, Employment, Emerging Labor Markets, and the Role of Education in Rural China, China Economic Review 13(2-3), 313-328.

Zhang, Jian, Linxiu Zhang, Scott Rozelle and Steve Boucher, 2006, "Self-Employment with Chinese Characteristics: The Forgotten Engine of Rural China's Growth," Contemporary Economic Policy, forthcoming.

Zhao, Yaohui, 1997, Labor Migration and Returns to Rural Education in China, American Journal of Agricultural Economics 79(4), 1278-87.

Zhao, Yaohui, 1999, Labor migration and earnings differences: The case of rural China, Economic Development and Cultural Change 47(4), 767-82. 
Table 1: Share of Labor Force Participating in Different Activities, Rural China

\begin{tabular}{lcccc} 
Sample & Farming & $\begin{array}{c}\text { Local Wage } \\
\text { Labor }\end{array}$ & Self-Employment & Migration \\
\hline CNBS (2001) & 0.670 & $0.330^{*}$ & 0.162 & 0.170 \\
Our Sample, All Individuals & 0.762 & 0.133 & 0.195 & \\
Our Sample, No Migrants & 0.847 & 0.161 & 0.142 & \\
Our Sample, Primary Activity & 0.676 & 0.122 &
\end{tabular}

Notes: CNBS statistics do not differentiate the self-employed from workers earning wages locally, nor do they report people of working age who do not work formally. As a result, the maximum possible share of labor working off-farm is reported in the "Local Wage" column. In our sample, workers can participate in both farming and one off-farm activity, or they can be idle. Therefore totals sum to more than 1 in rows 2 and 3. In row 4, we make our activity shares as comparable as possible to the CNBS figures, by reporting only the activity in which each individual spent the most time on, eliminating migrants.

Source: CNBS (2001); authors' survey. 
Table 2: Returns to Education in Rural China: Other Studies using the Mincer Method

\begin{tabular}{lcccc} 
Authors(Date) & $\begin{array}{c}\text { Dependent } \\
\text { Variable }\end{array}$ & $\begin{array}{c}\text { Years Data } \\
\text { Cover }\end{array}$ & $\begin{array}{c}\text { Analytical } \\
\text { Approach }\end{array}$ & $\begin{array}{c}\text { Returns to } \\
\text { Education }\end{array}$ \\
\hline Johnson and Chow (1997) & Yuan/month & 1988 & Individuals & 4.0 \\
Parish et al. (1995) & Yuan/year & 1993 & Individuals & $1.8-4.3$ \\
Yang (1997) & Yuan/day & 1990 & Individuals & 2.3 \\
Meng (1996) & Yuan/day & $1986-7$ & TVE workers & $0.7-1.1$ \\
Gregory and Meng (1995) & Yuan/day & $1986-7$ & TVE workers & $0.7-1.1$ \\
Ho et al. (2002) & Yuan/year & 1998 & TVE workers & $3.2-5.1$ \\
\hline
\end{tabular}


Table 3: Hourly Wages, by Type of Work, Cohort, and School Attendance

\begin{tabular}{lccc}
\hline & & \multicolumn{2}{c}{$\begin{array}{c}\text { Attended Any } \\
\text { Post-Primary School? }\end{array}$} \\
& $\mathrm{N}$ & no & yes \\
\hline All individuals & 1022 & 2.48 & $(2.66)$ \\
& & $(1.95)$ & $2.92^{* *}$ \\
Migrants & 571 & 2.25 & $(2.38)$ \\
& & $(1.63)$ & $2.77^{*}$ \\
Individuals under 35 & 672 & 2.43 & $(2.37)$ \\
& & $(2.19)$ & $2.83^{* *}$ \\
Migrants under 35 & 479 & 2.16 & $(2.38)$ \\
& & $(1.63)$ &
\end{tabular}

Notes: Standard deviations in parentheses. $* *$ - indicates difference between means significant at the 5\% level; *- indicates difference between means significant at the $10 \%$ level. 
Table 4: Effects of Education and Experience of Off-Farm Wages

\begin{tabular}{|c|c|c|c|c|c|}
\hline & (1) & (2) & (3) & (4) & (5) \\
\hline Years of & 0.063 & 0.064 & 0.065 & 0.105 & 0.029 \\
\hline Education & $(7.52)^{* *}$ & $(7.37)^{* *}$ & $(7.30)^{* *}$ & $(8.20)^{* *}$ & $(1.93)^{*}$ \\
\hline Years of & 0.025 & 0.031 & 0.035 & 0.084 & 0.026 \\
\hline Experience & $(4.70) * *$ & $(4.55)^{* *}$ & $(4.83)^{* *}$ & $(5.11)^{* *}$ & $(1.33)$ \\
\hline Experience, & -0.048 & -0.056 & -0.060 & -0.197 & -0.045 \\
\hline Squared (/100) & $(4.81)^{* *}$ & $(4.29)^{* *}$ & $(4.52)^{* *}$ & $(3.05)^{* *}$ & $(1.60)$ \\
\hline Gender & 0.220 & 0.210 & 0.221 & 0.116 & 0.390 \\
\hline$(1=$ male $)$ & $(3.53)^{* *}$ & $(3.48) * *$ & $(3.51)^{* *}$ & $(2.07)^{* *}$ & $(1.88)^{*}$ \\
\hline Marital Status & & -0.082 & -0.106 & -0.252 & 0.164 \\
\hline$(1=$ married $)$ & & $(0.98)$ & (1.18) & $(2.39) * *$ & $(0.75)$ \\
\hline Skill Training & 0.130 & 0.131 & 0.130 & 0.090 & 0.232 \\
\hline (1=yes) & $(2.67)^{* *}$ & $(2.64) * *$ & $(2.56)^{* *}$ & $(1.53)$ & $(2.69)^{* *}$ \\
\hline Father's Years & & & 0.011 & & \\
\hline of Education & & & $(1.60)$ & & \\
\hline Mother's Years of & & & -0.0001 & & \\
\hline Education & & & $(0.19)$ & & \\
\hline Inverse Mills & 0.234 & 0.219 & 0.232 & 0.301 & 0.079 \\
\hline Ratio & $(1.81)^{*}$ & $(1.68)^{*}$ & $(1.74)^{*}$ & $(2.14) * *$ & $(0.27)$ \\
\hline Number of Obs. & 3364 & 3364 & 3235 & 1515 & 1906 \\
\hline
\end{tabular}


Table 5: Returns to Schooling, by Type of Off-Farm Work

\begin{tabular}{lcccc}
\hline & \multicolumn{2}{c}{ All Individuals } & \multicolumn{2}{c}{ Individuals 35 and under } \\
& Migration & $\begin{array}{c}\text { Local Wage } \\
\text { Earning }\end{array}$ & Migration & $\begin{array}{c}\text { Local Wage } \\
\text { Earning }\end{array}$ \\
\hline Years of & 0.080 & 0.033 & 0.119 & 0.092 \\
Education & $(6.16)^{* *}$ & $(1.86)$ & $(7.97)^{* *}$ & $(2.75)^{* *}$ \\
Years of & 0.035 & 0.031 & 0.093 & 0.100 \\
Experience & $(3.42)^{* *}$ & $(2.50)^{* *}$ & $(4.82)^{* *}$ & $(3.07)^{* *}$ \\
Experience, & -0.076 & -0.038 & -0.236 & -0.218 \\
Squared (/100) & $(3.39)^{* *}$ & $(1.67)$ & $(2.74)^{* *}$ & $(2.01)^{* *}$ \\
Gender & 0.217 & 0.004 & 0.164 & 0.169 \\
(1=male) & $(3.08)^{* *}$ & $(0.03)$ & $(2.15)^{* *}$ & $(1.05)$ \\
Married? & -0.048 & 0.022 & -0.220 & -0.194 \\
(1=yes) & $(0.48)$ & $(0.16)$ & $(1.61)$ & $(0.93)$ \\
Skill Training? & 0.140 & 0.045 & 0.140 & 0.088 \\
(1=yes) & $(1.97)^{* *}$ & $(0.56)$ & $(1.44)$ & $(0.59)$ \\
& & & & \\
Inverse Mills & 0.174 & -0.229 & 0.251 & 0.186 \\
Ratio & $(1.37)$ & $(1.48)$ & $(1.50)$ & $(1.02)$ \\
Number of Obs. & 558 & 439 & 468 & 190 \\
\hline Nut
\end{tabular}

Notes: t-statistics based on bootstrapped standard errors in parentheses. ${ }^{* * \text {-indicates significance }}$ at the 5 percent level. Regressions use inverse Mills ratios from the specific outcome equations in the multinomial probit estimated in Appendix Table 3. For example, the inverse Mills ratio in column (1) comes from the results for the "migration" outcome in the appendix table. All standard errors were bootstrapped to take into account the two step estimation method. 
Table 6: Differential effects of primary education, and post-primary education on wages

\begin{tabular}{|c|c|c|c|c|}
\hline \multirow{3}{*}{$\begin{array}{l}\text { Explanatory } \\
\text { Variables }\end{array}$} & \multicolumn{2}{|c|}{ All Individuals } & \multicolumn{2}{|c|}{ Individuals 35 and under } \\
\hline & Selection & Wage & Selection & Wage \\
\hline & Equation & Equation & Equation & Equation \\
\hline Years of & 0.016 & 0.039 & 0.046 & 0.060 \\
\hline Primary School & $(2.58) * *$ & $(1.99)^{* *}$ & $(2.95)^{* *}$ & $(1.80)$ \\
\hline Years of Post- & 0.011 & 0.074 & 0.016 & 0.115 \\
\hline Primary School & $(2.29) * *$ & $(6.55)^{* *}$ & $(1.85)$ & $(7.86)^{* *}$ \\
\hline Years of & 0.000 & 0.033 & 0.021 & 0.088 \\
\hline Experience & $(0.10)$ & $(4.74)^{* *}$ & $(2.31)^{* *}$ & $(5.35)^{* *}$ \\
\hline Experience, & -0.013 & -0.060 & -0.065 & -0.229 \\
\hline Squared $(/ 100)$ & $(2.83) * *$ & $(4.53)^{* *}$ & (1.79) & $(3.39)^{* *}$ \\
\hline Gender & 0.197 & 0.206 & 0.172 & 0.113 \\
\hline$(1=$ male $)$ & $(11.35)^{* *}$ & $(3.43)^{* *}$ & $(5.50)^{* *}$ & $(2.02)^{* *}$ \\
\hline Marital Status & -0.200 & -0.079 & -0.338 & -0.230 \\
\hline$(1=$ married $)$ & $(6.26) * *$ & $(0.95)$ & $(8.27)^{* *}$ & $(2.16)^{* *}$ \\
\hline Skill Training? & 0.083 & 0.131 & 0.096 & 0.088 \\
\hline (1=yes) & $(3.80) * *$ & $(2.65)^{* *}$ & $(2.96)^{* *}$ & $(1.51)$ \\
\hline Log, Value of & -0.047 & & -0.077 & \\
\hline HH Assets, 1999 & $(6.69) * *$ & & $(6.28)^{* *}$ & \\
\hline Number of & -0.027 & & -0.035 & \\
\hline Male Workers & $(2.26)^{* *}$ & & $(1.65)$ & \\
\hline Number of & 0.068 & & 0.109 & \\
\hline Female Workers & $(6.26)^{* *}$ & & $(5.74)^{* *}$ & \\
\hline Land & -0.005 & & -0.006 & \\
\hline Endowment (mu) & $(3.30) * *$ & & $(2.22)^{* *}$ & \\
\hline Inverse Mills & & 0.205 & & 0.288 \\
\hline Ratio & & (1.58) & & $(2.06)^{* *}$ \\
\hline Number of Obs. & 3364 & 1023 & 1515 & 672 \\
\hline
\end{tabular}

Notes: t-statistics are in parentheses. $* *$ - indicates statistical significance at the $95 \%$ level. Provincial fixed effects are included in all equations. Experience is measured as years since the person left school if they went to school, and age -6 if they did not. All regressions are done using the two-step method proposed by Heckman (1974) and standard error calculations take the method into account. 
Table 7: Returns to Schooling, using alternative specifications

\begin{tabular}{lccc}
\hline & Their & \multicolumn{2}{c}{ Using 2000 Data Set } \\
Paper & $\begin{array}{c}\text { Their } \\
\text { Estimate }\end{array}$ & $\begin{array}{c}\text { Our } \\
\text { Method }\end{array}$ & Method \\
\hline Johnson and Chow (1997) & $4.0 \%$ & $3.0 \%$ & $6.5 \%$ \\
Parish et al. (1995) & $1.8-4.3 \%$ & $5.7 \%$ & $6.4 \%$ \\
Yang (1997) & $2.3 \%$ & $4.9 \%$ & $6.7 \%$ \\
Meng (1996) & $1.1 \%$ & $2.7 \%$ & $6.1 \%$ \\
Gregory and Meng (1995) & $1.1 \%$ & $2.7 \%$ & $6.1 \%$ \\
\hline
\end{tabular}

Notes: Estimates in column 2 were made by applying the methodology listed in the paper to the data set described in this paper. Column 3 includes the estimate for the data in this paper using our method, including only the subsample of workers used in their papers where appropriate. All estimates are significant at the 95 percent level. 


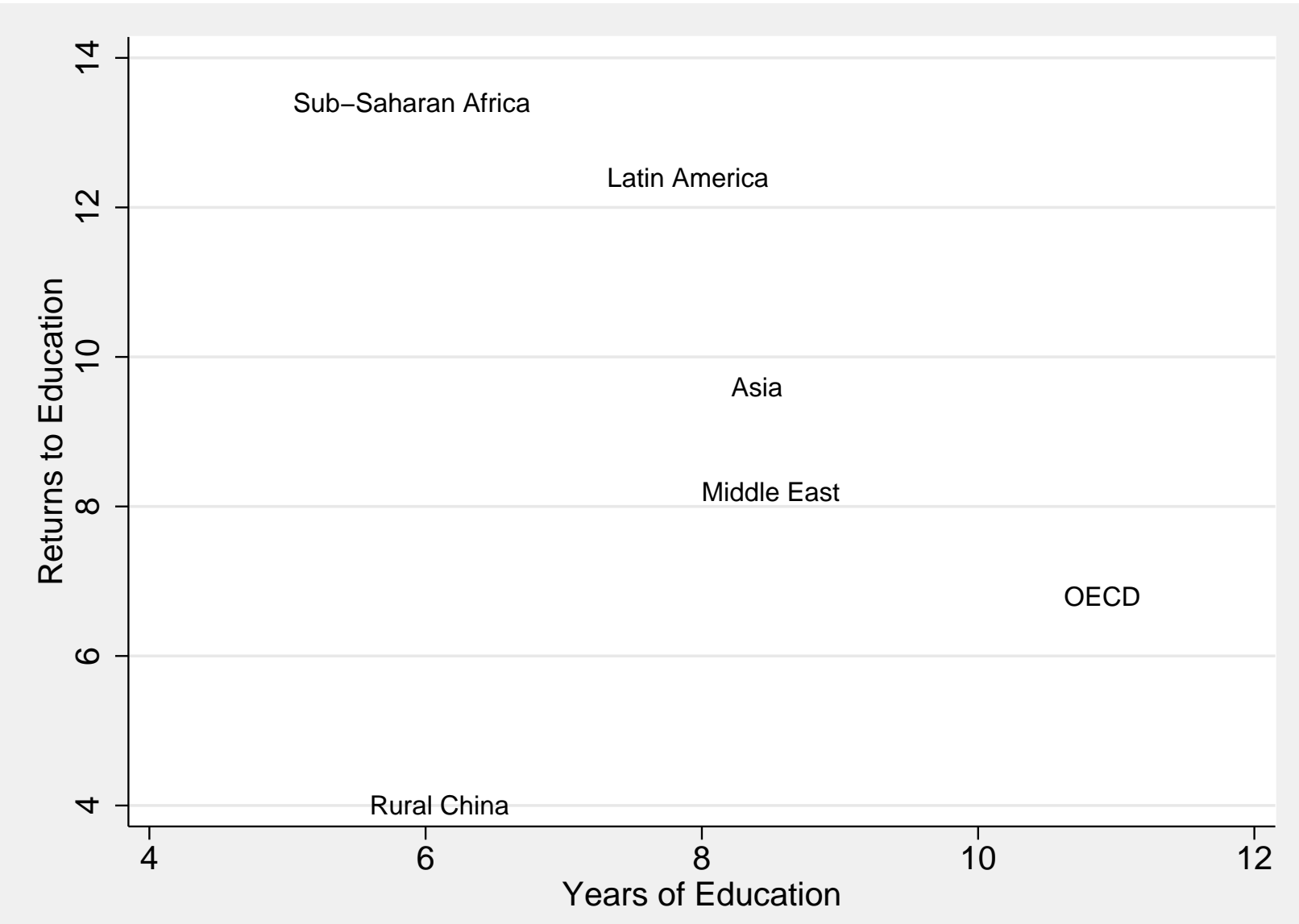

Notes: The five regional points are from Psacharopoulos (1994), Figure 2. "Asia" does not include Japan, the "Middle East" includes all non-OECD European countries in Europe and North Africa, and "Latin America" includes all countries in the Caribbean. The point for "Rural China" is based on the average level of education in the data used in this paper, and the returns to schooling are an average of the papers that use the Mincer method in Table 2.

Figure 1: Educational Attainment and Returns to Schooling 


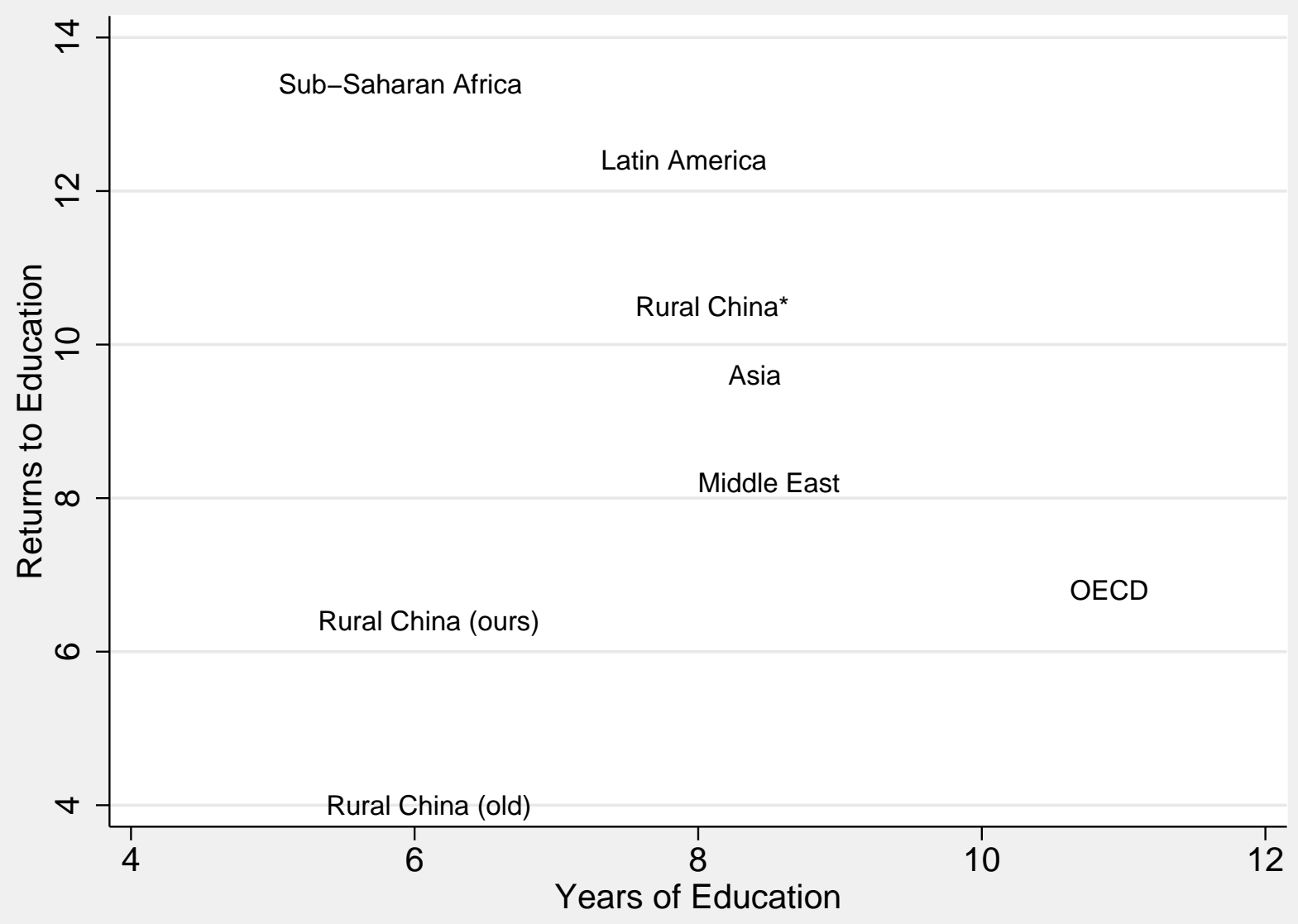

Notes: The five regional points are from Psacharopoulos (1994), Figure 2. The point for rural China are based on the average level of education and the returns to education found for individuals aged 35 and under in this paper. The point "Rural China (ours)" reflects our estimates for the entire sample; the point "Rural China*" reflects estimates for individuals 35 and under.

Figure 2: Educational Attainment and Returns to Education, Revisited 
Appendix Table 1: Summary statistics

\begin{tabular}{lcccc}
\hline & \multicolumn{2}{c}{ Off-Farm Workforce } & \multicolumn{2}{c}{ All Others } \\
Variable & Mean & Std. Dev. & Mean & Std. Dev. \\
\hline All individuals & 2.83 & 2.47 & - & - \\
Hourly wage & 7.68 & 2.97 & 5.45 & 3.56 \\
Years of Education & 5.45 & 1.33 & 4.25 & 2.32 \\
Years of Primary School & 2.22 & 2.15 & 1.19 & 1.76 \\
Years of Post-Prim. School & 17.46 & 13.27 & 29.48 & 15.82 \\
Years of Experience & 0.30 & 0.46 & 0.16 & 0.36 \\
Skill Training? & 0.25 & 0.43 & 0.18 & 0.38 \\
Good grades? (1=yes) & 0.13 & 0.34 & 0.11 & 0.31 \\
Bad grades? (1=yes) & 4.15 & 3.54 & 2.87 & 3.29 \\
Father's Years of Ed. & 2.17 & 3.08 & 1.19 & 2.48 \\
Mother's Years of Ed. & 0.56 & 0.50 & - & - \\
Migrant? (1=yes) & & & & - \\
Individuals 35 and under & 2.69 & 2.33 & - & 2.94 \\
Hourly wage & 8.13 & 2.68 & 7.16 & 1.49 \\
Years of Education & 5.68 & 0.94 & 5.30 & 1.95 \\
Years of Primary School & 2.44 & 2.17 & 1.86 & 7.02 \\
Years of Post-Prim. School & 9.49 & 6.33 & 12.97 & 0.41 \\
Years of Experience & 0.31 & 0.46 & 0.22 & 0.37 \\
Skill Training? & 0.23 & 0.42 & 0.17 & 0.36 \\
Good grades? (1=yes) & 0.15 & 0.35 & 0.15 & 3.41 \\
Bad grades? (1=yes) & 5.28 & 3.36 & 4.67 & 3.21 \\
Father's Years of Ed. & 2.96 & 3.32 & 2.54 & - \\
Mother's Years of Ed. & 0.72 & 0.45 & - & \\
Migrant? (1=yes) & & & & \\
\hline Notes 1022 & & & & \\
\end{tabular}

Notes: 1022 individuals are off-farm workers and are included in columns 1-2; 2341 individuals are not and are included in columns 3-4. Of the off-farm workers, 672 are 35 or under, and 841 are 35 or under and do not work off-farm. For 128 observations, the father's education level was unknown, so these observations are not included. 
Appendix Table 2: Returns to Schooling, by Age Group

\begin{tabular}{|c|c|c|c|c|c|}
\hline & (1) & (2) & (3) & (4) & (5) \\
\hline Years of & 0.011 & 0.013 & 0.013 & 0.024 & 0.008 \\
\hline Education & $(4.03) * *$ & $(7.37)^{* *}$ & $(3.57)^{* *}$ & $(8.20)^{* *}$ & $(2.27) * *$ \\
\hline Years of & -0.011 & 0.001 & 0.002 & 0.026 & -0.002 \\
\hline Experience & $(6.00)^{* *}$ & $(0.22)$ & $(0.57)$ & $(2.93)^{* *}$ & $(1.07)$ \\
\hline Experience, & 0.003 & -0.013 & -0.015 & -0.088 & -0.005 \\
\hline Squared $(/ 100)$ & $(0.78)$ & $(3.13) * *$ & $(3.24)^{* *}$ & $(2.62) * *$ & $(1.86)^{*}$ \\
\hline Gender & 0.078 & 0.198 & 0.202 & 0.173 & 0.198 \\
\hline (1=male) & $(3.60) * *$ & $(11.44)^{* *}$ & $(11.50)^{* *}$ & $(5.53)^{* *}$ & $(11.11)^{* *}$ \\
\hline Married? & & -0.200 & -0.221 & -0.335 & -0.001 \\
\hline (1=yes) & & $(6.29) * *$ & $(6.65)^{* *}$ & $(8.21)^{* *}$ & $(0.01)$ \\
\hline Skill Training? & 0.205 & 0.083 & 0.088 & 0.098 & 0.040 \\
\hline (1=yes) & $(11.93)^{* *}$ & $(3.82)^{* *}$ & $(3.96)^{* *}$ & $(3.02)^{* *}$ & $(1.67)^{*}$ \\
\hline Father's Years & & & -0.001 & & \\
\hline of Education & & & $(0.042)$ & & \\
\hline Mother's Years of & & & -0.0001 & & \\
\hline Education & & & $(0.54)$ & & \\
\hline \multicolumn{6}{|l|}{ Instruments } \\
\hline Log, Value of HH & -0.051 & -0.047 & -0.048 & -0.076 & -0.021 \\
\hline Assets, 1999 & $(7.20)^{* *}$ & $(6.69) * *$ & $(6.61)^{* *}$ & $(6.22)^{* *}$ & $(3.03) * *$ \\
\hline Number of Male & -0.020 & -0.027 & -0.026 & -0.039 & -0.009 \\
\hline Workers & $(1.68)^{*}$ & $(2.28) * *$ & $(2.09)^{* *}$ & $(1.85)^{*}$ & $(0.66)$ \\
\hline Number of Female & 0.067 & 0.068 & 0.066 & 0.109 & 0.021 \\
\hline Workers & $(6.20) * *$ & $(6.31)^{* *}$ & $(6.01)^{* *}$ & $(5.76)^{* * *}$ & $(1.75)^{*}$ \\
\hline Land & -0.005 & -0.005 & -0.005 & -0.005 & -0.005 \\
\hline Endowment $(\mathrm{mu})$ & $(3.40)^{* *}$ & $(3.30)^{* *}$ & $(3.40)^{* *}$ & $(2.16)^{* *}$ & $(2.73)^{* *}$ \\
\hline Number of Obs. & 3364 & 3364 & 3235 & 1515 & 1906 \\
\hline
\end{tabular}


Appendix Table 3: Multinomial Probit Regressions Describing Activity Choice

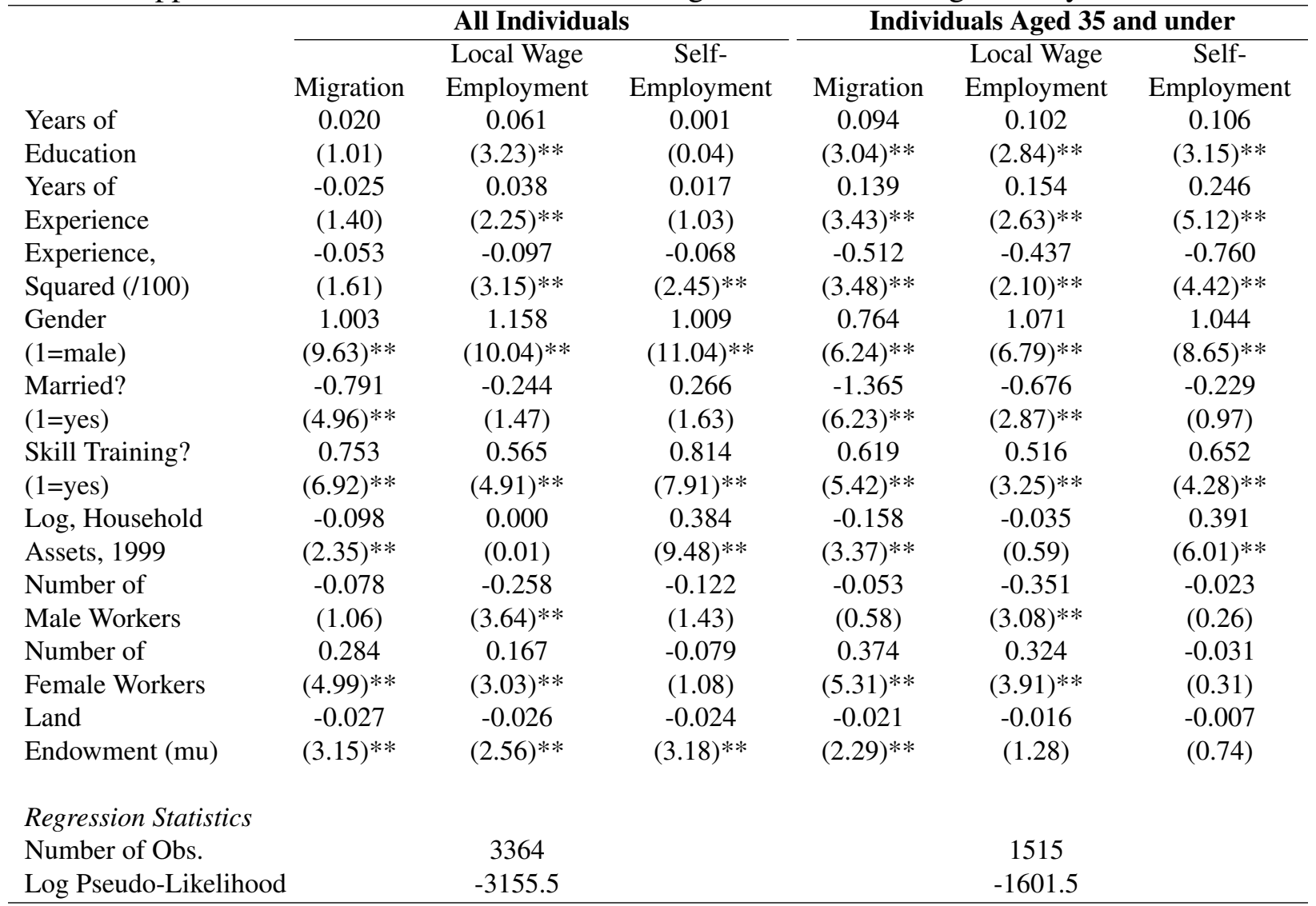

Notes: Asymptotic $z$-statistics in parentheses are based on standard errors clustered at the village level. **- indicates significance at the 5 percent level. Columns 1-3 represent the first regression; columns 4-6 represent the second regression. Both regressions include provincial dummy variables. 